\title{
Types of mathematical tasks used in secondary classroom instruction
}

Valbona Berisha, Ruzhdi Bytyqi

Faculty of Education, University of Prishtina, Kosovo

\begin{tabular}{l} 
Article Info \\
\hline Article history: \\
Received Mar 26, 2020 \\
Revised Jun 22, 2020 \\
Accepted Jul 15, 2020 \\
\hline
\end{tabular}

\section{Keywords:}

Categorization

Curriculum requirements

Features analysis

Mathematical tasks

Secondary school

\begin{abstract}
This study examined the quality and types of mathematical tasks used for classroom instruction in an upper secondary school - gymnasium. All the mathematical tasks presented in nine different school classrooms during the first semester of the school year 2018/2019 were analysed against a 5D analytical framework. The dimensions of the individual task analysis were contextual features; the answer forms required; forms of presentation; types of required mathematical activity and cognitive demands involved. Performed analysis gived perspective on the learning opportunities offered in classroom instruction for building mathematical competencies specified in the current state education curriculum. The results indicate that the selection of tasks was not in accordance with the curriculum requirements. Mostly, teachers used close-ended, non-applicative, lower-level cognitive tasks presented in symbolic form, promoting operations and calculations as a central activity. These types of tasks are usually associated with knowledge and skills of lower orders. In this case, classroom instruction had low potential and very little room left to build a significant portion of competencies and learning outcomes of higher orders.
\end{abstract}

This is an open access article under the CC BY-SA license.

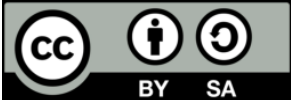

\section{Corresponding Author:}

Valbona Berisha,

Faculty of Education,

University of Prishtina,

Rr. "Agim Ramadani", p.n. 10000 Prishtinë, Kosovo.

Email: valbona.berisha@uni-pr.edu

\section{INTRODUCTION}

There are efforts visible all around the globe aimed at reforming education systems. The operationalization of the key competences for life is the main objective of teaching and learning. Students' real needs and interests are addressed, so they can acquire the skills and habits needed to respond critically and creatively to real life situations in order to handle and solve problems constructively. Nowadays, mathematics is seen as a developer and facilitator of logical, systematically, critical and creative student's thinking [1]. Lately, special efforts have been made for the acquisition of mathematical competencies within core competencies, or "the ability to understand, judge, do, and use mathematics" [2]. Contemporary mathematics teaching and assessment focuses on competency attainment levels, with continuous feedback and follow-up in competency performance improvement. The major responsibility in this regard is to determine the tasks to be used in classroom instruction. The issue of selecting mathematical tasks for classroom instruction is of great interest for mathematics education researchers [2-7], since tasks are an essential part of mathematics teaching and learning [8].

Effective teaching and construction of mathematical competences relates mainly to the use of rich, varied, meaningful and worthwhile mathematical tasks $[9,10]$. A proper task selection and the way they are 
presented and processed with students are key factors that determine the potential and opportunities for deep and meaningful conceptual learning [11]. Solving of familiar tasks, for instance, often does not require any kind of conceptual understanding [12], so it does not bring any benefit in that direction. Proper selection, among other things, implies the use of diverse types of tasks that cover a wide range of learning outcomes. A narrow range of task types matches with a narrow range of learning outcomes. Based on recent research, such as [7, 13-15] the use of textbooks as the sole source for classroom task selection is scarce. Usually, textbooks do not facilitate the development of a full range of mathematical competences. Therefore, teachers' commitment in this regard is vital [16]. The use of various resources for task selection, as well as formulating, designing and modifying own tasks is of utmost importance. Selection of tasks, formulating and changing them are important aspects of lesson planning [17].

Moreover, different types of tasks have different weight, role and potential in mathematics teaching and learning [18, 19]. Not all mathematical tasks offer the same learning opportunities [20]. An appropriate choice of tasks helps students move to higher levels of mathematical thinking and learning [21]. The weight, role, and potential that mathematical tasks possess in terms of learning mathematics are determined mainly by analysing their essential features and the demands they place on students. A very important feature of mathematical tasks is the level of cognitive demand placed in order to carry on a task. The level of cognitive demand placed by a mathematical task represents the way and type of thinking needed to solve a task. The cognitive level of the task is usually defined based on the depth of conceptual mathematical thinking. There are several commonly used taxonomies to structure and classify mathematical tasks based on their cognitive requirements. For the present analysis, the Level Cognitive Demand (LCD) framework developed by Stein \& Smith is used [22].

The real-world contexts involved with a mathematical task represent a feature that plays a significant role in linking school mathematics tasks with students' real experiences. Therefore, the categorisation of a mathematical task according to the type, amount and nature of the context embedded in it is a very frequent dimension of task characterization. There are several frameworks and methods for categorizing mathematical tasks based on the type, extent and nature of the contexts involved. The current categorisation of tasks based on their contextual features is adopted according to the views of authors in [23].

Traditional mathematics classroom instruction relies heavily on calculations and the symbolic form of communication. The redefinition of mathematical competence, on the other hand, is associated with other types of mathematical activity besides calculating. In [24], four types of mathematical activity are identified: representation and modelling activity, operation and calculation activity, interpretation activity, argumentation and reasoning activity. In $[10,24]$ mathematical tasks are differentiated and categorised based on the main activity/activities required to carry on a task. This analytical dimension provides information on classroom instruction potential for developing the full range of mathematical skills.

Another important dimension of differentiating mathematical tasks is their form of presentation. The presentation of tasks can be done in different modes and forms - verbal, symbolic, visual and combined one. The forms of communication in mathematics classrooms are interrelated and depend on the variety of forms of presentation of mathematical tasks. All the mentioned forms must be included in today's mathematics classroom instruction. Different and multiple presentation and communication forms facilitate the development of representation, modelling and communication skills. The current categorisation of tasks based on their form of presentation is adopted according to the views of authors in [23].

The answer type required by the tasks used for the classroom instruction indicates whether the teaching approach is open or closed. An open teaching approach creates a rich environment for creativity, autonomy and deeper levels of conceptual understanding. It is commonly conveyed through incorporating illstructured tasks that have more than one solving path and several or many solutions. A closed teaching approach relies mainly on fully defined tasks, which usually have only one way of solving and only one solution. The current categorisation of tasks based on the answer type required is adopted according to the views of authors in [23].

Kosova is the youngest state in Europe. It gained independence in 2008, after ending war against Serbian occupation in 1999. One of the most pressing issues in post-war Kosova was the advancement of the education system. The old education system inherited from the Yugoslav era and Serbian occupation was totally dysfunctional. Mathematics curriculum was a purely traditional one with teacher-centered teaching, an abstract approach to mathematical concepts, rote learning, and a focus on developing students' skills for automated calculations, operations, algorithms and procedures [15]. Two state education curricula have been developed since the end of the war. The first one was issued in the 2003/2004 school year. The first after-war curriculum brought important, constructivist changes to the entire education system. It brought a lot of change in mathematics teaching and learning, too. It broadened the range of mathematics learning outcomes, introduced the concept of problem solving, exploration and higher order thinking skills. But, Kosova was still too far behind the developed part of Europe. The unfulfilled need to build a modern 
and compatible education system with the developed part of the world, very soon brought us to the current position, moments after the implementation of the second post-war curriculum. The claim of the new curriculum is to form a modern school system based on standards and competencies [25]. As for the mathematics part of it, it resembles most contemporary mathematics curricula influenced by the PISA mathematical framework and the fact that mathematics must be at the service of society, of daily life and rapid technological development. Among other things, the core curriculum for upper secondary school sets up the main mathematics competencies that rely heavily on problem solving, with a particular focus on contextual problems; argumentation and reasoning; communication; making connections; reasoning and proof; representation; modelling and use of ICT [26]. Yet, kosovar students have performed very poorly in PISA 2015 and PISA 2018, since Kosovo began to participate in this international study. Not a local study has yet dealt with the factors associated with the revealed weaknesses related to mathematical competencies and student's skills in problem solving. Though the issuance of the new curriculum leads in the right direction, still, this large and relatively fast curriculum shift needs to be associated with necessary practical transitions, which is the most difficult part of educational reform. The actual study deals exactly with this very question - if there is an alignment between curriculum intentions and classroom practices. The issue in question will be investigated through the analysis and characterization of the tasks used for mathematics classroom instruction.

\section{RESEARCH METHOD}

This study examined the quality and types of tasks used for mathematics classroom instruction in an upper secondary school - gymnasium, located in one of the Kosova municipalities. All the tasks used during the school year 2018/2019 in nine classrooms of this school (grades 10 - 12), were analyzed against a five-dimensional analytical framework. The number of the mathematical tasks analyzed was 2131 . All nine classrooms had different mathematics teachers. The tasks were collected directly from teachers and student classroom notes. Table 1 shows the distribution of tasks for classrooms.

Table 1. The distribution of the collected tasks according to the classrooms

\begin{tabular}{cccccccccc}
\hline Classrooms & $10 \mathrm{a}$ & $10 \mathrm{~b}$ & $10 \mathrm{c}$ & $11 \mathrm{a}$ & $11 \mathrm{~b}$ & $11 \mathrm{c}$ & $12 \mathrm{a}$ & $12 \mathrm{~b}$ & $12 \mathrm{c}$ \\
\hline Number of tasks & 421 & 426 & 260 & 161 & 181 & 100 & 251 & 224 & 107 \\
\hline
\end{tabular}

The utilised analytical framework represented a combination of five analytical dimensions. The analytical dimensions included contextual features; the answer forms required; forms of presentation; types of required mathematical activity and cognitive demands involved. The framework was built having in mind the specific range of curriculum requirements that directed the classroom instruction in this case. Table 2 provides a summary of all five analytical dimensions by the categories used in the study and their brief description. The features analysed provide an overview of the learning opportunities offered in the classroom instruction. The current study utilized a content analysis design based on quantitative approach. For the data processing we have used descriptive statistics (frequencies and percentages). 
Table 2. The analytical framework used in the study

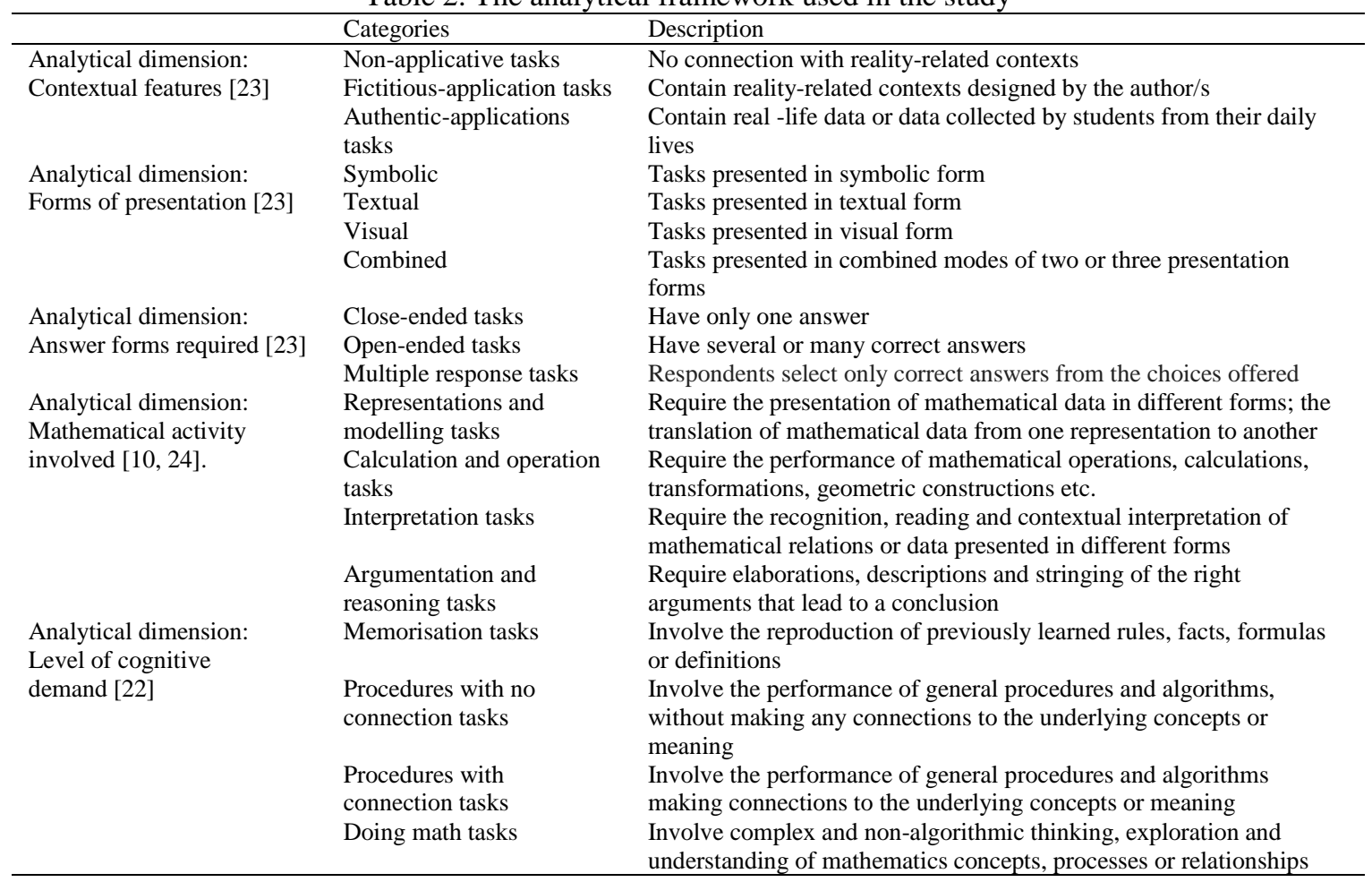

\section{RESULTS AND DISCUSSION}

Figure 1 gives an overview of the contextual characteristics of the tasks analyzed according to the classrooms. The graph shows a deep imbalance in the representation of existing categories. Vast majority of tasks presented in all nine classrooms are of non-applicative type. Exactly $99.30 \%$ of them belong in this category. The other two categories are almost unrepresented. Both contain $0.70 \%$ of the tasks, with only one of the tasks being of an authentic-applicative type. But, challenging students with contextual problems is one of the explicit requirements of our curriculum. Students should "describe and solve problem situations that arise within mathematics and in contexts from other fields as well as from shared experiences of everyday life [26]. We must recall here the very poor performance of Kosovar students the first two times of participation in PISA 2015 and PISA 2018. One of the major factors of this poor performance appears to be our students' non-exposure to contextual tasks. This extreme non-exposure has also been documented in several other local studies that have examined the presence of contexts in mathematics textbooks [27-29] at different schooling levels, and classroom assessment in elementary school $[25,30]$.

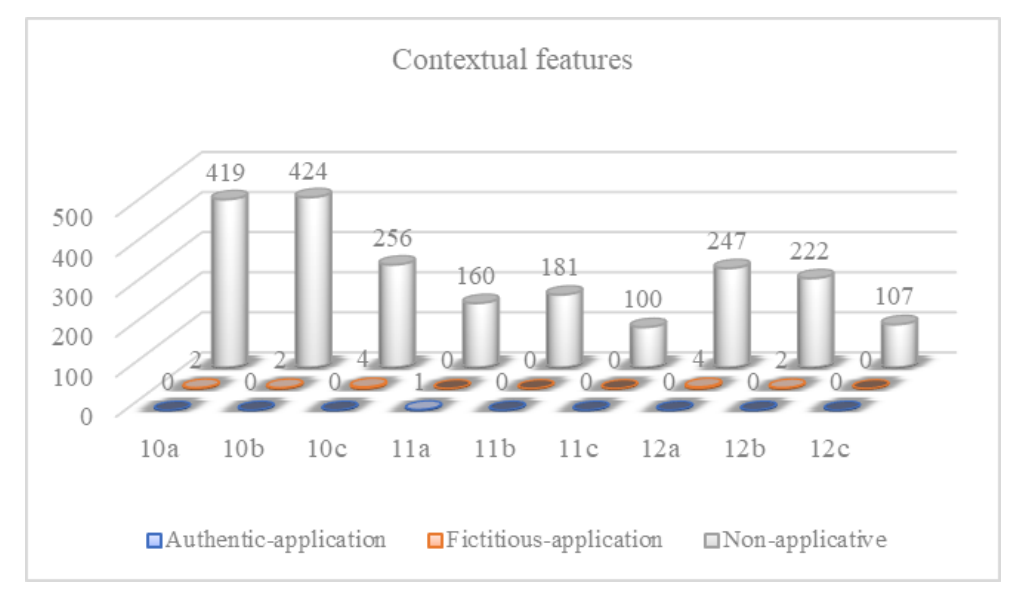

Figure 1. Contextual features of the analyzed tasks according to the classrooms 
The findings on the forms of task presentation according to the classrooms are shown in Figure 2. Vast majority of the used tasks, $80.38 \%$, are presented in symbolic form. Only $7.13 \%$ of the tasks are presented with text, while $4.22 \%$ of the tasks have a visual form. The remaining $8.26 \%$ are of combined form. Moreover, the identified visual representations are mainly in the form of numerical set diagrams. Other types of visual representations such as pictures related with real-world contexts, graphs etc. are not represented at all. Findings indicate that the central form of mathematics classroom communication is the symbolic one. Much advantage is given to symbolic form compared to other forms of presenting ideas, concepts and problems. In this case, both textual and visual form of mathematical communication is highly neglected, despite the fact these two forms have an important function in mathematics teaching and learning. Both forms facilitate the modelling, representation and problem-solving skills.

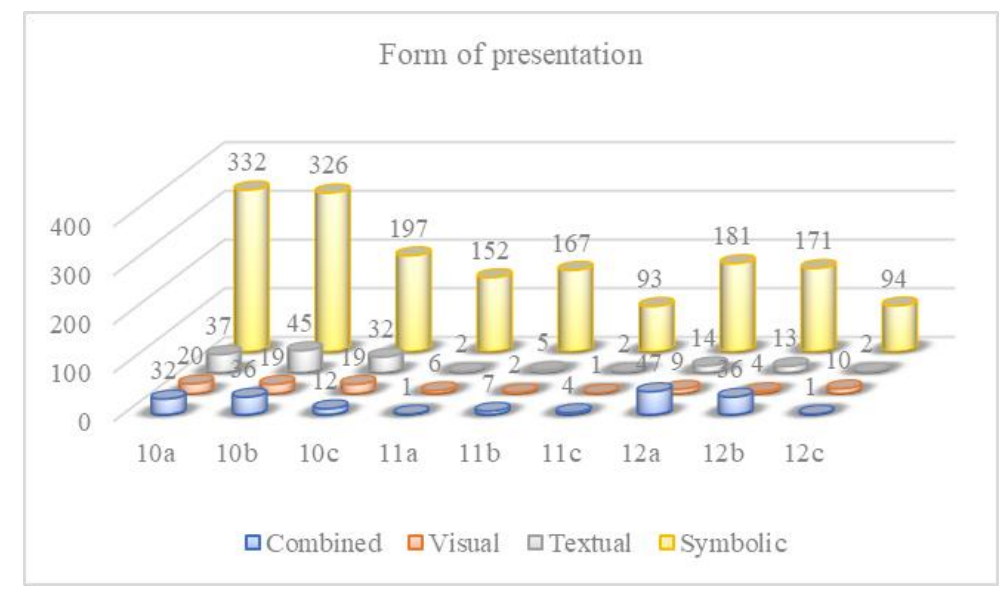

Figure 2. Forms of presentation of the analyzed tasks according to the classrooms

Figure 3 reveals the results on the answer form required by the tasks. Findings indicate that vast majority of tasks, $95.21 \%$ of them, are close-ended ones. Eight tasks or $0.38 \%$ of the total number of tasks analysed are open-ended ones, and the remaining $4.41 \%$ are of multiple-choice type. Results indicate a strictly closed approach to mathematics instruction. This type of instruction does not allow much room for the construction of a wide range of skills related to creativity, production and autonomous strategies. Current findings combined with very similar findings from a recent local study examining test design as an assessment tool in elementary mathematics classrooms [25] argue that an open approach to mathematics teaching and learning is not at all familiar to Kosovar teachers.

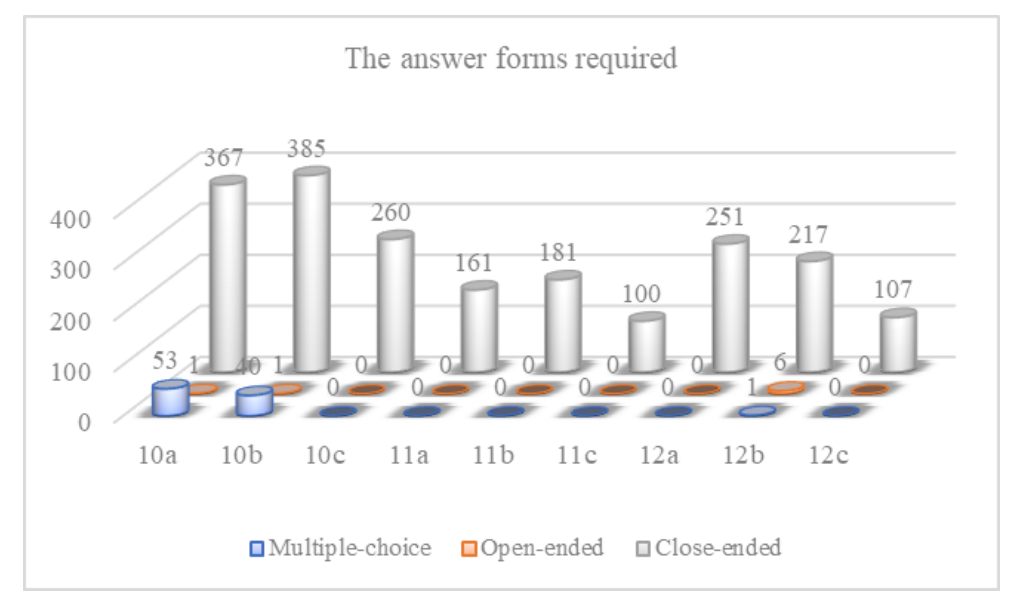

Figure 3. The answer forms required in the analysed tasks according to the classrooms 
Figure 4 gives an insight into the mathematical activities required of students in order to solve the tasks. The coding of tasks was done according to the main activity required in the task. There are $85.97 \%$ of the total number of tasks analysed fall in the category of mathematical calculations and operations. Representation or modelling is required in $12.62 \%$ of tasks as the main activity. Most of such tasks were presented in the tenth grade. A small portion of tasks, $5.11 \%$ of them, require interpretation of mathematical representations, expressions or formulas and only $4.79 \%$ of tasks require argumentation or reasoning as a central activity.The results on mathematical activities indicate a rather traditional way of mathematics teaching and learning. Students are trained mainly in the domain of calculations and operations. Interpreting skills as well as argumentation and reasoning skills are almost completely overlooked.

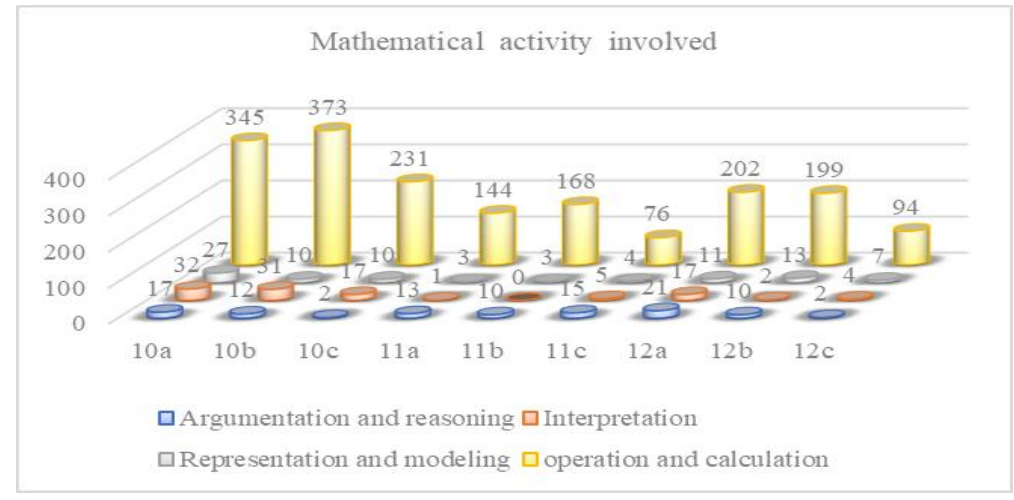

Figure 4. Mathematical activities involved with the tasks analyzed according to the classrooms

Findings related to the cognitive demands conveyed by the analysed tasks are shown in Figure 5. $87.66 \%$ of tasks are of low cognitive level. The major fraction of these low cognitive level tasks is procedural ones, with no relation to the concepts and meanings behind the procedures needed for solving them. A small fraction of these tasks are memorization ones. Those are carried on with the help of memorized facts and rules. This group of tasks includes many cases where students might carry out the task in a very meaningless and almost absent-minded way. Only $3.52 \%$ of the total numbers of the tasks relate to autonomous solution strategies and strategies, while the rest of the higher cognitive level tasks can be solved using general procedures associated with the concepts and meanings behind these procedures. Once again, the results do not indicate alignment with higher-order curriculum requirements. Most of the tasks analyzed promote memorization and automated procedures applications, they do not deal with conceptual and meaningful understanding at all. Only a small fraction of tasks has the potential to develop critical and creative thinking through deep conceptual understanding. The time spent for classroom instruction is not well managed, given the cognitive demands of presented tasks " $\ldots$ if more time were spent in classroom with students engaged in working on cognitively demanding nonroutine tasks, as opposed to exercises in which a known procedure is practiced, student's opportunities for thinking and learning would likely be enhance" [11].

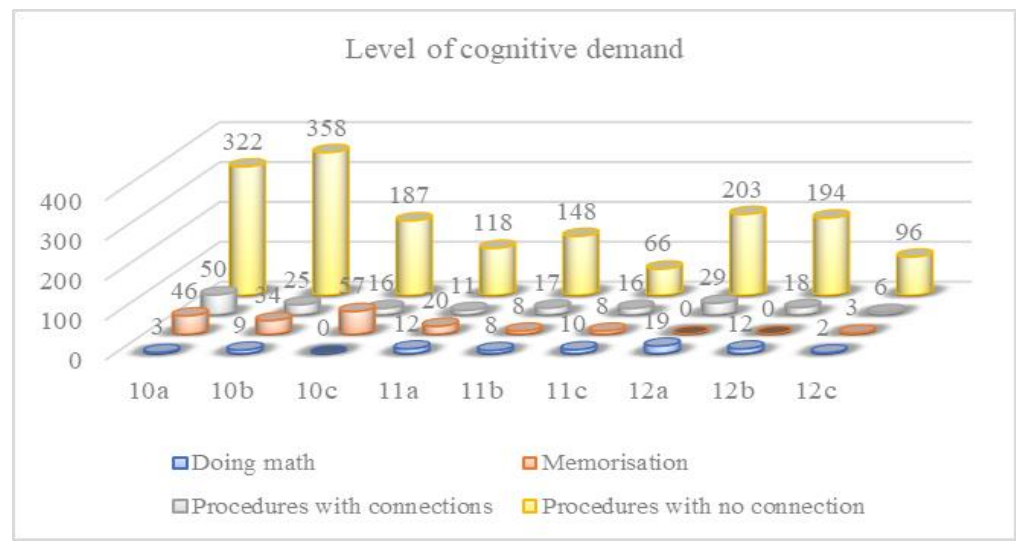

Figure 5. LCD of tasks analyzed according to the classrooms 


\section{CONCLUSION}

The findings indicate a significant imbalance in representation of the different categories within each of the analytical dimensions examined. Given that all the participating categories have their own importance and diverse role in the building of intended competences and learning outcomes, all of them must have a balanced representation in classroom instruction. In such a case of huge imbalances, negative implications for learning are very expectable. The current Kosovar curriculum sets out a wide range of intended learning outcomes for mathematics. Besides the factual knowledge and procedural skills, its intentions are attainment of higher order thinking and reasoning skills, critical and creative thinking and real-world competencies. In addition to the noted imbalances between categories, the findings show that most of the tasks used for classroom instruction relate to categories that mainly contribute to lower order learning outcomes.

Mostly, teachers used close-ended, non-applicative, lower-level cognitive tasks presented in symbolic form, promoting operations and calculations as a central activity. These tasks typically emphasize memorization and promote operations and calculations through automated procedures. Tasks which have the potential for developing critical and creative thinking; deep conceptual understanding; interpretation, application and modelling skills - are very rare ones. As far as the opportunities offered by the selected types of tasks are considered, the classroom instruction in this case, is not well aligned with the current state curriculum requirements for the field of mathematics. In conclusion, it can be said that based on the performed analysis on the types of tasks used for classroom instruction, the implemented classroom curriculum is not in line with the state intended curriculum. The tasks used enable very little or no space for vide range of intended learning outcomes of higher orders.

\section{REFERENCES}

[1] Mutmainah, et al, "Effectiveness of experiential learning-based teaching material in Mathematics," International Journal of Evaluation and Research in Education (IJERE), vol. 8, no. 1, pp. 57-63, 2019.

[2] J. Lithner, "Principles for designing mathematical tasks that enhance imitative and creative reasoning," ZDM, Mathematics Education, vol. 49, no. 6, pp. 937-949, 2017.

[3] P. Sullivan, et al, "Converting mathematics tasks to learning opportunities: An important aspect of knowledge for mathematics teaching," Mathematics Education Research Journal, vol. 21, no. 1, pp. 85-105, 2009.

[4] A. Coles and L. Brown, "Making distinctions in task design and student activity," In A. Watson, M. Ohtani, J. Ainley, J. Bolite Frant, M. Doorman, C. Kieran, A. Leung, C. Margolinas, P. Sullivan, D. Thompson, \& Y. Yang (Eds.) Proceedings of ICMI Study 22: Task Design in Mathematics Education, pp. 183-192, Oxford: International Commission on Mathematics Instruction, 2013.

[5] C. Margolinas, "Task design in mathematics education," Proceedings of ICMI Study 22, Oxford, United Kingdom 2014.

[6] D. Clarke, H. Strømskag, H. L. Johnson, A. Bikner-Ahsbahs and K. Gardner, Mathematical tasks and the student. In P. Liljedahl, C. Nicol, S. Oesterle, \& D. Allan (Eds.) Proceedings of the 38th Conference of the International Group for Psychology of Mathematics Education and the 36th Conference of the North American Chapter of the Psychology of Mathematics Education, vol. 1, pp. 117-143, Vancouver, Canada: PME, 2014.

[7] A. Watson and M. Ohtani, "Themes and issues in mathematics education concerning task design," In A. Watson \& M. Ohtani (Eds.), Task design in mathematics education: An ICMI study, Berlin: Springer, 2015.

[8] NCTM, Principles and standards for school mathematics, Reston, VA: Author, 2000.

[9] S. Breen and A. O'Shea, "Mathematical thinking and task design," Irish Mathematical Society Bulletin, vol. 66, pp. 39-49, Nov 2010

[10] D. Gracin, "Requirements in mathematics textbooks: a five-dimensional analysis of textbook exercises and examples," International Journal of Mathematical Education in Science and Technology, vol. 49, no. 7, pp. 1003-1024, 2018.

[11] M. A. Simon and R. Tzur, "Explicating the role of mathematical tasks in conceptual learning: An elaboration of the hypothetical learning trajectory," Mathematical thinking and learning, vol. 6, no. 2, pp. 91-104, 2004.

[12] J. Boesen, J. Lithner, and T. Palm, "The relation between types of assessment tasks and the mathematical reasoning students use," Educational Studies in Mathematics, vol. 75, no. 1, pp. 89-105, 2010.

[13] H. L. Johnson, A. Coles, and D. Clarke, "Mathematical tasks and the student: navigating "tensions of intentions" between designers, teachers, and students," ZDM, vol. 49, no. 6, pp. 813-822, 2017.

[14] K. Jones and B. Pepin, "Research on mathematics teachers as partners in task design," Journal of Mathematics Teacher Education, vol. 19, no. 2-3, pp. 105-121, 2016.

[15] V. Berisha, et al, "Mismatch between curriculum intentions and textbook design: an assessment of mathematics textbooks for lower secondary school in Kosovo," GSTF Journal on Education, vol. 2, no. 2, pp. 31-35, 2015.

[16] S. Rezat and R. Sträßer, "From the didactical triangle to the socio-didactical tetrahedron: artifacts as fundamental constituents of the didactical situation," ZDM-The International Journal on Mathematics Education, vol. 44, no. 5, pp. 641-651, 2012.

[17] D. Pimm, Part III commentary: "Who knows best? Tales of ordination, subordination, and insubordination," In Mathematics Teachers at Work, Routledge, pp. 210-216, 2011. 
[18] Y. Li, "A comparison of problems that follow selected content presentations in American and Chinese mathematics textbooks," Journal for Research in Mathematics Education, vol. 31, no. 2, pp. 234-241, 2000.

[19] B. Pepin and L. Haggarty, "Making connections and seeking understanding: Mathematical tasks in English, French and German textbooks," AERA 7, pp. 1-15, 2007

[20] M. K. Stein, M. S. Smith., M. A. Henningsen, and E. A. Silver, Standards-based math instruction: A casebook for professional development, Teachers College Press, 2009.

[21] T. Adiguzel and Y. Akpinar, "Improving School Children's Mathematical Word Problem Solving Skills through Computer-Based Multiple Representations," Association for Educational Communications and Technology, Chicago, IL, October 19-23, pp. 1-10, 2004.

[22] I. Bayazit, "Quality of the tasks in the new Turkish elementary mathematics textbooks: The case of proportional reasoning," International Journal of Science and Mathematics Education, vol. 11, no. 3, pp. 651-682, 2012.

[23] Y. Zhu and L. Fan, "Focus on the representation of problem types in intended curriculum: A comparison of selected mathematics textbooks from Mainland China and the United States," International Journal of Science and Mathematics Education, vol. 4, no. 4, pp. 609-626, 2006.

[24] IDM, Standards for the mathematical competencies of Austrian students at the end of the 8th grade, Alpen-Adria Universität, Klagenfurt, 2007.

[25] MASHT, Korniza Kurrikulare e Arsimit Parauniveristar të Kosovës, (e rishikuar), 2017. [Online]. Available: https://masht.rks-gov.net/uploads/2017/03/korniza-kurrikulare-finale.pdf

[26] MASHT, Kurrikula Bërthamë për Arsimin e Mesëm të Lartë (Gjimnazet-klasa X, XI, XII), 2017. [Online]. Available: https://masht.rks-gov.net/uploads/2017/03/korniza-berthame-3-final.pdf

[27] R. Salla, "Characteristics of the tasks presented in math textbooks for grade 10," Unpublished master thesis, University of Prishtina, 2018.

[28] N. Kurteshi, "The representation of real contexts in mathematics textbooks for lower secondary school," Unpublished master thesis. University of Prishtina, 2017.

[29] V. Berisha, H. Jashari, Xh. Thaqi, and Sh. Klinaku, "Assessment of Mathematics Textbooks Potential in Terms of Student's Motivation and Comprehension," Journal of Education and Practice, vol. 4, no. 28, pp. 33-17, 2013.

[30] A. Murati, "Test as an assessment tool in mathematics," Unpublished master thesis, University of Prishtina, 2018. 